\title{
Effect of nano-magnesium oxide and harmonic scalpel on lung lobectomy healing in dogs: Clinical and cytokine study
}

\author{
O.A. Bader ${ }^{1}\left[\right.$ and M.J. Eesa ${ }^{2}(\mathbb{D}$ \\ ${ }^{1}$ Department of Surgery and Theriogenology, College of Veterinary Medicine, University of Mosul, Mosul, ${ }^{2}$ Department of \\ Surgery and Obstetrics, College of Veterinary Medicine, University of Baghdad, Baghdad, Iraq
}

\begin{tabular}{l} 
Article information \\
\hline Article history: \\
Received July 11, 2020 \\
Accepted January 3, 2021 \\
Available online October 1,2021 \\
\hline Keywords: \\
Thoracoscope \\
Nano magnesium oxide \\
Cytokine \\
Lung \\
Dog \\
\hline Correspondence: \\
O.A. Bader \\
omaralbader2003@ uomosul.edu.iq
\end{tabular}

DOI: 10.33899/ijvs.2021.127611.1514, (C)Authors, 2021, College of Veterinary Medicine, University of Mosul.

This is an open access article under the CC BY 4.0 license (http://creativecommons.org/licenses/by/4.0/).

\section{Introduction}

Lung can be involved in a variety of disease processes, including cancer, trauma, lung lobe torsion, chronic lung diseases and cystic fibrosis. In some of these diseases, treatment usually depending on removing of lung lobes to cure them (1). Laparoscopic devices provide several benefits more than the open surgery such as less surgical trauma, shorter time, safe, less complications and less pain and stress to the animals (2). Thoracoscopic surgery has gained widespread acceptance of diagnostic and therapeutic procedures for pulmonary and non-pulmonary thoracic lesions in veterinary surgery due to reducing of both time of recovery and postoperative morbidity. Regardless of this, thoracoscopy offered good results when used on complete or partial lobectomies (3). Ultrasonic harmonic scalpel dissection devices have been introduced as an alternative to electrosurgical devices. These devices use ultrasonic waves to dissect the tissue, making it possible to perform a more sophisticated dissection with a narrower circumference of collateral thermal damage to the surrounding tissue compared to the damage caused by monopolar electrosurgical devices. Furthermore, bleeding control and dissection can be performed simultaneously and there is a lack of surgical smoke with less charring, consequently, a clearer visual field can be secured (4). Nanotechnology is leading the technological uprising in the world, which is associated with materials with new properties because of 
their small size, significantly unlike their bulk complements, and significantly dissimilar biological, chemical, and physical properties (5). Between recognized metal oxide NPs, magnesium oxide $(\mathrm{MgO})$ has been broadly studied because it is exclusive rigid with high ionic properties, crystal structure and humble stoichiometry (6). $\mathrm{MgO}$ has good bioactive capabilities, biocompatibility, and magnesium ions have no toxicity (7). $\mathrm{MgO} \mathrm{NP}$ is one of nanomaterials whose effects on living cells are persisted not known (8).

Many studies are claiming that $\mathrm{MgO} \mathrm{NP}$, play positive roles in cells or animals, $\mathrm{MgO} \mathrm{NP}$ has an anti-inflammatory and analgesic effect.

\section{Materials and methods}

Twenty-four adult local breed male dogs, the average ages between 2-3 years and weighing between $15-25 \mathrm{Kg}$ were used in this experimental study. Dogs were divided randomly into two equal groups. Animals were housed 14 days before surgical intervention. All dogs were treated against internal and external parasites by using Ivermectin $1 \%$ at a dose of $0.2-0.4 \mathrm{mg} / \mathrm{kg} \mathrm{B}$.W. subcutaneously and repeated after 14 days (9). The animal undergoing operation was kept for 24 and 6 hours without food and water respectively, tidal volume was measured preoperatively by using a spirometer (Figure 1A).

\section{Surgical operation}

Area at the right thoracic region was prepared for aseptic surgery from first to last ribs. The animal has been given atropine sulfate $0.04 \mathrm{mg} / \mathrm{kg}$ B.W subcutaneously as a premedication, then ten minutes later the animal injected by $2.5 \%$ thiopental $12 \mathrm{mg} / \mathrm{kg}$ B.W intravenously (10), to facilitate the introduction of endotracheal tube. Then the animal was connected to an inhalation anesthetic machine (closed method) which is supported with positive pressure ventilator using halothane-oxygen mixture 1-1.5 minimum alveolar concentration (MAC) value of halothane and oxygen flow 1-2.5 L/minute. The animal was controlled on the surgical table at lateral recumbence with the head kept a little high. Ringer lactate solution at a dose of 8-10 $\mathrm{ml} / \mathrm{kg} /$ hours was given intravenously pre, during and postoperation (11).

A small skin incision about $1 \mathrm{~cm}$ was done between the tenth and eleventh ribs in the midway of rib length, then pursing suture technique was done around the incision site using No. 2/0 polyglactin 910 suture material. Then a blunt dissection was made to open the intercostal muscles to allow insertion of the trocar and cannula $10 \mathrm{~mm}$ into thoracic space for establishment of the pneumo-thorax. The key parameters of insufflator of the intrathoracic pressure were fixed at 3-6 $\mathrm{mm} / \mathrm{Hg}$ according to the size of animal's chest. Telescope was inserted through this port to investigate the right lung and surrounding structure. Then two other ports were required for lung lobectomy, the first one $5 \mathrm{~mm}$ was placed in the ventral third of the ninth intercostal space (for grasper) while the other $10 \mathrm{~mm}$ was placed in the dorsal third of the ninth intercostal space (for harmonic scalpel and clip applicator) using same procedure for induced of first port and under the vision of telescope. After localization of the appropriate lung lobe hilus, the grasper was used to hold the right middle lobe (Figure 1B), clip applicator was used for ligature of the bronchus and blood vessel using double titanium clips $10 \mathrm{~mm}$ (Figure 2). After that the right middle lobe was coagulated and transected by using harmonic scalpel above the titanium clips, through coagulation and cutting mode at levels of 3-5 on footswitches of device (Figure 3), then the resected lobe was removed through enlarged dorsal port to permit exiting the lung lobe (Figure $4 \mathrm{~A})$. In the treated group same as control group but $\mathrm{MgO} \mathrm{NP}$ solution which is prepared by dissolving $\mathrm{MgO}$ NP in distal water, was infiltrated in and around the stump of the resected lobe using a special thoracoscopic needle (Figure 4B) in a dose of $100 \mu \mathrm{g} / \mathrm{ml}$ (12). The stump was observed for air leakage or bleeding, in which normal saline was pushed in the thoracic cavity at the stump site to make sure if there is air leakage from the stump then the saline was removed through suction- irrigation machine. Deflation of pneumothorax was done then instruments, telescope and ports were removed and the ports incision sites were closed subsequently by using simple continuous technique using polyglactin 910 No. 2/0 for closure of pleura, intercostal muscles and subcutaneous tissues. Skin was closed by simple interrupted suture technique using silk No. 0. Tramadol at a dose of $1-5 \mathrm{mg} / \mathrm{kg} \mathrm{B}$.W twice daily was injected at the first 2 days in a constant dose after surgery to control pain (10). Skin suture was removed after 10 days' post-operation.

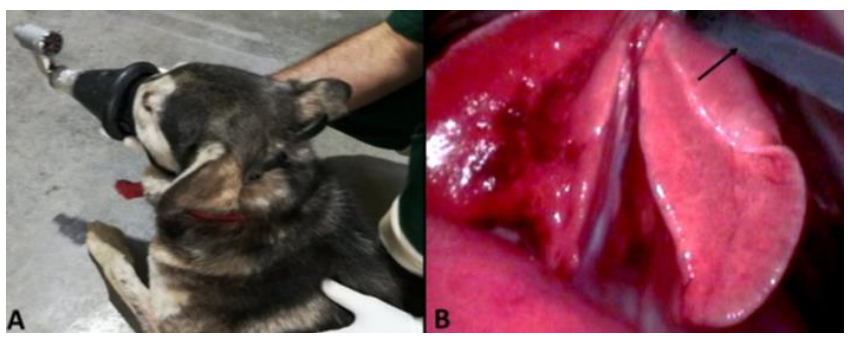

Figure 1: Measuring the tidal volume preoperatively using spirometer (A). Holding of right middle lobe by grasper (arrow) (B).

\section{Blood sampling}

Blood was collected from experimental animals before the surgical intervention which considered as zero time then at $1,3,5,7,14,21,28$ and 35 days after surgical operation. The blood collected by clean test tube contain special gelatin for separation of serum at room temperature through centrifugation at 3500 RPM for 10 minutes, serum was then aspirated by a pipette and transferred to a plastic vial. Serum samples were analyzed by using ELISA and diagnostic kits for interleukin-6 and TNF which were specific for canine. 


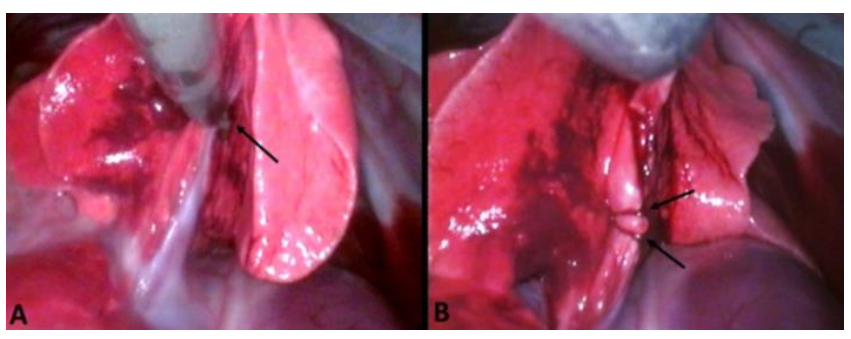

Figure 2: Placing of titanium clips around bronchus and blood vessel by clip applicator (arrow) (A). Placing of double titanium clips around bronchus and blood vessels (arrow) (B).

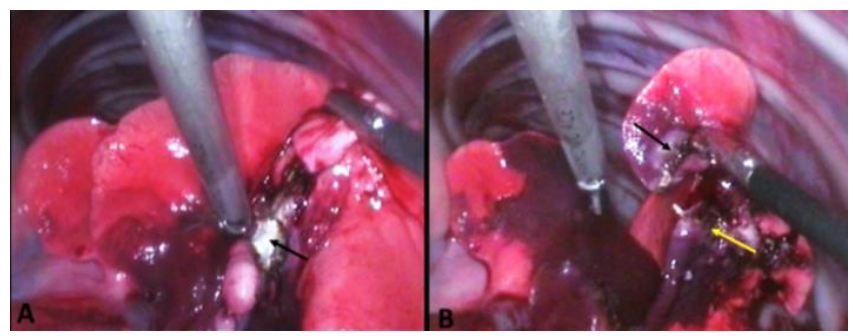

Figure 3: Cutting of the right middle lobe using harmonic scalpel (arrow) (A). Complete cutting of right middle lobe (black arrow) and stump (yellow arrow) (B).

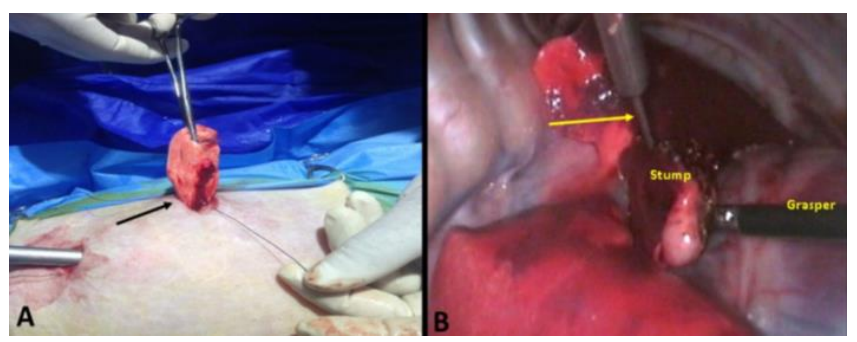

Figure 4: Removing of the resected lobe from enlarged port site (arrow) (A). Infiltration of MgO NPs solution in the line of resected lobe (stump) using special thoracoscopic needle (arrow) (B).

\section{Statistical analysis}

Computer package (Sigma plot V12.0/SYSTAT software) was used to conduct the parameter analysis. Data were presented as means $\pm \mathrm{SE}$ (standard error) and were analyzed using one-way analysis of variance (ANOVA) and t-test with the significant level set on $\mathrm{P}<0.01$ and the differences among the groups were determined by Duncan's multiple range test (13).

\section{Results}

\section{Physiological evaluations}

The animals were observed daily and all clinical observations were recorded, including animals' activity (posture, motion, alert to surrounding, appetite, urination and defection). In which most of the dogs in both groups took 2 4 days' post-operation to gain full activity, except 4 dogs in control group remain inactive during the first 4-7 days' postoperation. Body temperature was within the normal range in the treated group, while animals in the control group show slight elevation especially in the first 3-4 days' postoperation (dogs in both groups show slight decrease in the body temperature at the end of operation and continued 1-2 hour after operation).

\section{$\mathrm{O}_{2}$ and $\mathrm{Co}_{2}$ measurement}

The concentration of $\mathrm{O}_{2}$ and $\mathrm{Co}_{2}$ were measured using capnograph apparatus pre, during and postoperatively. The concentration of $\mathrm{O}_{2}$ pre and during operation was between $90-100 \%$ of the blood and it maintained at this concentration with fresh $\mathrm{O}_{2}$ which is continued even after animal recovery until the occurrence of body adaptation and these phenomena sometimes may take 2-3 hours post operation. But in some cases, and after stop of fresh $\mathrm{O}_{2}$ supply post operation the concentration of $\mathrm{O}_{2}$ was decreased into $70 \%$. While the concentration of $\mathrm{Co}_{2}$ pre-operatively was between $30-35 \%$ of the blood and during the operation it maintained at this concentration, the $\mathrm{Co}_{2}$ concentration showed not raised above $50 \%$ or less than $25 \%$ (normal range between 25 $50 \%$ ). After operation, the $\mathrm{CO}_{2}$ concentration was disturbed up and down from the normal range but it returns to the normal level a few hours after the operation.

\section{Heart and respiratory rates}

In this study the heart and respiratory rates clearly differed between pre and post operation, the heart rate was within the normal limit pre and during the operation which was mainly about 85 beats/minute, and when the animal started to recover the heart rate started to elevated with irregular method reaching about $150-160$ beats/minute when the dogs completely recovered and this irregularity continued for about 3-5 hours post-operation which then the heart rate started to regulate and reached to 100-110 beats/minute on the first 24 hours. Heart rate then was started to decrease gradually reaching within the normal range at days 2-3 in all treated animals, while in control group lasted until days 7, except 4 dogs which were the heart rate slightly elevated until three weeks of operation.

Respiratory rate also recorded an elevation in their rhythm post operation after being within the normal rate 23 breaths/minute. Respiratory rhythm started to elevated immediately after patient recovery reaching about 80-90 breaths/minute in the first hours (3-5 hours), then the rate started to regulate and decreased as the patient adapted to his condition reaching to about $40-50$ breath/minute on the first day post operation. Then the rate start lessened reaching within the normal range at day's 4-5 post operation. This criterion of respiration noticed on all treated animals, while on control group regularity of respiratory rate lasted until 710 days' post-operation, except 4 animals of giving slightly elevation from normal range until the biopsy time. During 
exercise, the treated group seems to show normal breathing, while in the control group 4 animals tired quickly and laying down after slight exercise, and the rate of respiration increased and take a period of time to be decreased.

\section{Tidal volume}

The tidal volume varies from one animal to another; moderate tidal volume was about $450-500 \mathrm{ml}$. The tidal volume was decreased comparing with its first reading and this decrease was about $15-20 \%$ from the pre-operative reading. At the first hour's post-operation the measuring of tidal volume did not give us an acceptable reading due to irregular respiration, but when the respiration becomes regular decreasing tidal volume was noticed. Then the tidal volume began to increase reaching to its previous reading at 3-4 days in all treated animals, while in control group most animals take about 10 days to be within previous reading except 4 animals which their tidal volume was not reached to the previous reading but near of it after 3 weeks post operation.

\section{Interleukin-6}

The results of IL-6 showed a significant difference in the mean values of the IL- 6 between control and treatment groups in all periods at $\mathrm{P}<0.01$ when comparing the two groups on $1^{\text {st }}, 3^{\text {rd }}, 5^{\text {th }}, 7^{\text {th }}, 14^{\text {th }}, 21^{\text {th }}, 28^{\text {th }}$ and $35^{\text {th }}$ days postoperatively (Figure $5 \mathrm{~A}$ and $\mathrm{B}$ ), also there is a significant difference in the mean values of the IL- 6 in the same group when comparing different days at $\mathrm{P}<0.01$ (Figure $7 \mathrm{~A}$ ). and treated groups at different period post-operation.

\section{Tumor necrosis factor- $\alpha$}

The results of TNF- $\alpha$ showed a significant difference in the mean values of the TNF between control and treatment groups in all periods at $\mathrm{P}<0.01$ when comparing the two groups on $1^{\text {st }}, 3^{\text {rd }}, 5^{\text {th }}, 7^{\text {th }}, 14^{\text {th }}, 21^{\text {th }}, 28^{\text {th }}$ and $35^{\text {th }}$ days postoperatively (Figure $6 \mathrm{~A}$ and $\mathrm{B}$ ), also there is a significant difference in the mean values of the TNF- $\alpha$ in the same group when comparing different days at $\mathrm{P}<0.01$ (Figure $7 \mathrm{~B}$ ).

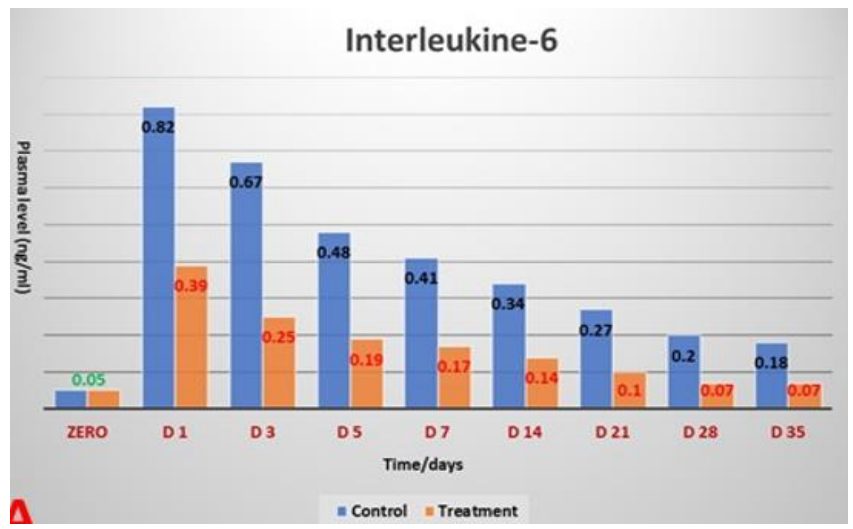

Figure 5: Show the difference values of IL-6 in control

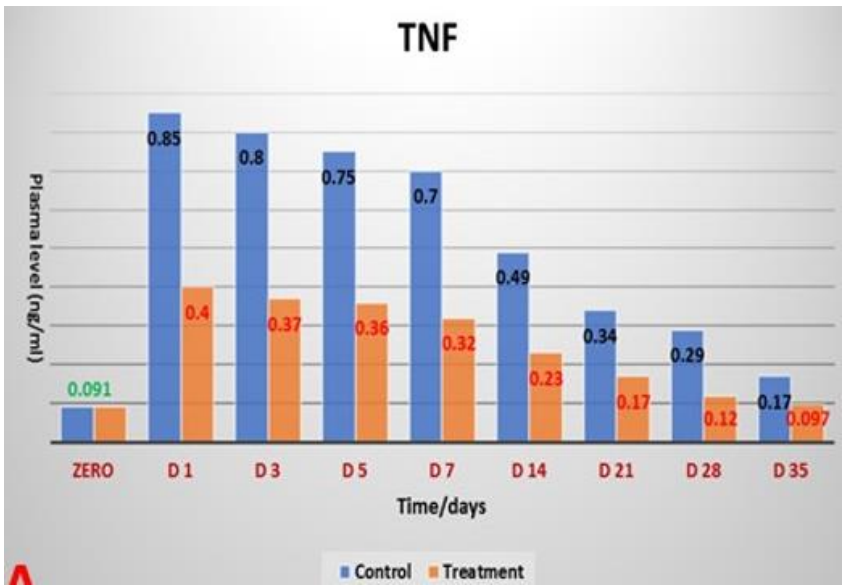

Figure 6: Show the difference values of TNF- $\alpha$ in control and treated groups at different period post-operation.
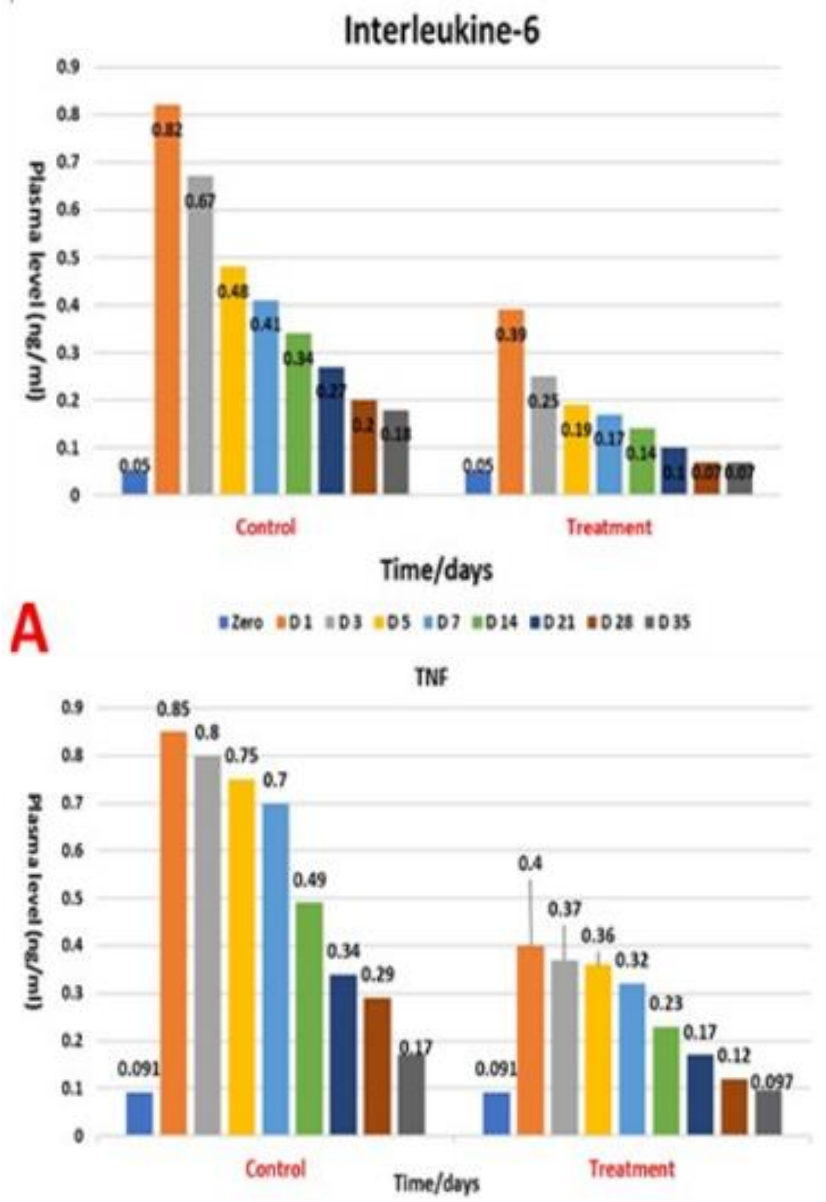

B

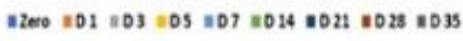

Figure 7: Show the difference values of IL-6 within each group at different period post-operation (A). The difference values of TNF- $\alpha$ within each group at different period postoperation (B). 


\section{Discussion}

\section{Physiological parameters}

In both groups the body temperature was slightly decreased 1-2 hours post operation, this might be due to the effect of inhalation anesthesia on thermo-regulatory center, this change agreed with Kurz (14), who illustrated that both anesthesia and surgery dramatically alter body temperature control, and as a result of intraoperative core, temperature below 1 to $3^{\circ} \mathrm{C}$. In treated group, body temperature was within the normal range, while in control group show slight elevation; this time was elapse into 3-4 days' post operation to return into normal level. The variation might be due to effect of nano materials as antibacterial activities to decrease the inflammatory reaction, this finding is agreed with Maji et al. (15), which demonstrated that magnesium oxide nanoparticles possessed statistically significantly antibacterial activities.

In both groups, the heart rates were within normal level during operation but start to elevate at recovery period and irregularity continue for about 3-5 hours' post-operation, then regulate on the 24 hours post operation. Heart rate started to decreased gradually and reaching within normal level at 2-3 days' post-operation in all treated animals, while in control group lasted until 7 days post-operation. This irregularity, elevation then decrease and became within the normal level might be due to that thoracoscopic lobectomy has been demonstrated to be associated with postoperative complications and this agreed with Erol et al. (16), who described that the most common complication observed in patients for whom lung resection performed are postoperative cardiac complications. Postoperative atrial arrhythmias are common after pulmonary lobectomy and they are associated with stroke, death, increased length of stay and readmission. Identifying at-risk patients will allow for tailored prophylaxis strategies.

The respiratory rate was consecutive with change of heart rate, in which elevating in the first 3-5 hours' post-operation and started to regulate and decrease on 24 hours' postoperation, these start to reach within normal range at days 45 post-operation. This criterion of respiration noticed on all treated animals, while on control group regularity of respiratory rate lasted until 7-10 days' post operation. This phenomenon might be related with adaptability of the lung to compensate of the deprivation of the right middle lung lobe, these results agreed with Wakamatsu et al. (17), who explained that dogs were capable of respiratory compensation immediately after pneumonectomy and maintained appropriate oxygenation and remained hemodynamically stable. Dogs undergoing pneumonectomy may have already begun to institute compensatory mechanisms for reduced pulmonary function, explaining the superior function of existing pulmonary parenchyma. In addition, the contralateral lung lobes may be able to expand to a greater degree after pneumonectomy compared to single lobectomy.
In treated group during exercise, there is tolerance to it and shows normal breathing after exercise, but in control group some animals were tired, lying down or increase in respiratory rate level after exercise. This difference between two groups might be due to the action of MgO NPs on the promotion of healing prosses. These observations of our results provided by other workers Kim et al. (18), who demonstrate that lobectomy patients suffered significant reduction of functional reserve, with almost equal deterioration between lung function and exercise capacity. The pulmonary functional reserve and exercise capacity of the patient decrease as a result of resection of the lung parenchyma after thoracotomy. Depending on the amount of lung tissue resected, a decrease in breathing capacity, in diffusion capacity, or maximal cardiac output occur which limits maximum oxygen consumption (19).

Another reason for the reduction in exercise capacity and functional reserve can be explained as pain and chest wall limitation due to surgical injury, besides lung parenchyma loss (20). Despite the introduction of techniques that cause less injury to the chest wall, such as video-assisted thoracoscopic surgery, patients after lung resection experience a significant decrease in exercise tolerance within the first 2 weeks after surgery which originated from a complex spectrum of interacting factors including the inhibiting effects of thoracic pain, the loss of pulmonary volume corresponding to the resected segments (19). Also, Torabi et al. (21), demonstrated that Nano-MgO induces greater analgesic and anti-inflammatory effects through central and peripheral mechanisms and the nanoparticles at lower doses were able to improve anxiety and pain perception in the presence of acute stress, so that in treated group animals show rapid exercise tolerance rather than in control group.

\section{$\mathrm{Blood}_{2}$ and $\mathrm{Co}_{2}$ findings}

The normal concertation of blood $\mathrm{O}_{2}$ in dogs was between $90-100 \%$, but after lung thoracoscopic lobectomy in our study, the concentration was disturbed and reached to $70 \%$ so that the animal was continued to supply with $\mathrm{O}_{2}$ till 2-3 hours' post-operation to an adaptation of patient to maintain the level of $\mathrm{O}_{2}$ within the accepted range. This decrease of $\mathrm{O}_{2}$ concentration in blood after lobectomy might be due to the effect of air exchange between alveoli and interstitial tissue, as a result of middle lobe loss of right lung. Maggiore et al. (22), explained that post-extubation respiratory failure following major surgery is common and a substantial proportion of the patients requires prolonged mechanical ventilation and prolonged intensive care unit or hospital stay. Postoperative pulmonary complications such as hypercapnia and atelectasis which increase mortality are particularly attributable to adverse prognosis in patients with thorax surgery especially with lobectomy. In some of the patients specially those who have lobectomy it is ineffective in compensating for loss in lung volume or in maintaining gas exchange, so a positive airway pressure to improves 
oxygenation by increasing end-expiratory lung volume is indicated.

\section{Tidal volume}

The moderate tidal volume was about $450-500 \mathrm{ml}$, these were decreased for about $15-20 \%$ from the pre operation, then after the respiratory rate became regular, the tidal volume begins to increase and reaching within normal level at day 3-4 days in all treated animals, while in control group most animals take about 10 days to be within previous reading, these findings conformable with Nomori et al. (23), which explained that loss of lung tissue can severely deteriorate the function of ventilating the lungs which may lead to respiratory failure, additional loss of lung tissue contributes to their disability, postoperative pulmonary function was different according to the lobe resected. The reduction of lung function after surgical resection of lung parenchyma depends on the parenchyma lost. There was a significant decrease in pulmonary function due to a greater loss of functional lung volume at immediate postoperative periods.

\section{Interleukin-6 evaluation}

The level of interleukin- 6 in the present study showed a significant difference between both groups along the period of $1^{\text {st }}, 3^{\text {rd }}, 5^{\text {th }}, 7^{\text {th }}, 14^{\text {th }}, 21^{\text {th }}, 28^{\text {th }}$ and $35^{\text {th }}$ days post-operation at the level of $\mathrm{P}<0.01$. This result of high level of interleukin6 in control group compared with low level of interleukin-6 in treated group might be attributed to inflammation, this finding was agreed with Störmann et al. (24), who reported that physiological concentrations of IL-6 are relatively low in serum. These concentrations are rapidly elevated in response to inflammation, trauma or injury and in critical illness and may reach a high quantitative level in the $\mathrm{mg} / \mathrm{mL}$ of serum. The magnitude of IL-6 elevation correlates with the extent of tissue trauma/injury severity; IL-6 measurements are often better predictors of disease activity than assessments of $\mathrm{C}$ reactive protein (CRP). Elevated concentrations of IL-6 are, therefore, an early indicator of infection or inflammation and are integral to immunological host defense. Also, Qiao et al. (25), demonstrate that in large animal models like canine and porcine serum concentration of IL-6 reaches its peak within $24 \mathrm{~h}$ after injury and this could be useful for the prediction of post-traumatic complications.

There is a significant difference within the same group at different period post-operation. These results were revealed that decreased level of interleukin- 6 gradually on the elapse of time post-operation. These consequences might be associated with a decrease of inflammation, this scientific agree with Das et al. (26), who referred that serum interleukin-6 levels peaked immediately after surgery and gradually declined to preoperative level on postoperative days, but it remained persistently higher in a patient who developed postoperative complication. Good postoperative analgesic nursing can relieve the excessive stress reaction, regulate the level of cytokines, balance the levels of inflammatory and anti-inflammatory factors and relieve the immunosuppression. The intraoperative analgesia and postoperative patient-controlled analgesia can not only relieve the postoperative pain, but also reduce the level of proinflammatory factors in blood and thus inhibit the excessive stress reaction, so that in treated group the level of IL- 6 and TNF- $\alpha$ was lower than the control group, this might be due to the anti-inflammatory and analgesic effect on nano $\mathrm{MgO}$. These results were approved via other researchers like Moeini-Nodeh et al. (27), who reported that MgO NPs can play a positive role in cells and animals. MgO NPs have an anti-inflammatory role also have protection against oxidative stress, lipid peroxidation, cytotoxicity and diabetic disorders.

\section{Tumor necrosis factor- $\alpha$ evaluation}

The level of tumor necrosis factor in our study shows significant difference between two groups at the period of $1^{\text {st }}$, $3^{\text {rd }}, 5^{\text {th }}, 7^{\text {th }}, 14^{\text {th }}, 21^{\text {th }}, 28^{\text {th }}$ and $35^{\text {th }}$ days post-operation at the level of $\mathrm{P}<0.01$, which appeared that the level of tumor necrosis factor was high in the control group compared with a treated group. Tumor necrosis factor is secreted mainly by activated macrophages and lymphocytes in response to cell damage caused by infection and inflammatory response, this coincided with Faz-Lopez et al. (28), who demonstrated that TNF- $\alpha$ levels are elevated in both the serum and the bronchoalveolar lavage fluid which participates in the pathophysiology of the systemic inflammatory response in critically ill patients such as acute lung injury.

Also, Liu and Tang (29), demonstrate that TNF- $\alpha$ is a key cytokine involved in the generation of the acute inflammatory response. This inflammatory cytokine is primarily produced by immune cells, such as monocytes and macrophages, but a number of non-immune cell types, including fibroblasts, neurons, keratinocytes and smooth muscle cells, also produce TNF- $\alpha$. The plasma level of $\mathrm{TNF}-\alpha$ is increased in response to severe traumatic injury, low TNF- $\alpha$ levels have been reported to promote the remodeling or replacement of injured tissue by stimulating fibroblast growth. Peak plasma TNF- $\alpha$ levels were detected $24 \mathrm{~h}$ after injury and then gradually subsided. Furthermore, Fehaid and Taniguchi (30), demonstrated that TNF- $\alpha$ is a major proinflammatory cytokine and is usually detected in the early stage of cell inflammation and has many known signal transduction pathways such as the induction of cell death. In contrast, in cells exposed to both TNF- $\alpha$ and NPs, the nanoparticles non-specifically bind to TNFR1 and TNF$\alpha$ binds specifically with the same receptor, forming a TNFR1-TNF $\alpha$-NPs complex which then enters the cells by receptor-mediated endocytosis. TNF- $\alpha$ is then released from the receptor and induces apoptosis.

The receptors might still bind to NPs, thus disturbing the receptor's shape, molecular weight, and characteristics, leading to disturbance of its normal pathway of being recycled to the cell membrane, resulting in less TNFR1 on the cell membrane and more inside the cells. This molecular mechanism explains how TNFR1 would play a role in 
increasing the cellular uptake of NPs and reducing TNF- $\alpha$ induced apoptosis as a result.

The mechanism clarifies that the NPs - TNFR1 complex hinder the re-expression pathway of the receptors on the cell membrane leading to decrease in the TNF- $\alpha$ signal transduction and its apoptotic effect. These mechanisms were agreed with our results in treated group in which decrease level of TNF- $\alpha$ in treated group compared with control group.

There is a significant difference in TNF- $\alpha$ concentration within the same group at different period this may be due to elevation of TNF- $\alpha$ concentration in the early stage of inflammation and tissue damage, this coincided with Shapouri-Moghaddam et al. (31), who exhibited that TNF- $\alpha$ is secreted by activated M1 macrophages and plays a dominant role in host defense reaction and a variety of biologic effects, such as cell differentiation, proliferation and multiple pro-inflammatory effects. The blood concentration of TNF- $\alpha$ is significantly increased which indicated the expression of pro-inflammatory cytokines and the intensified inflammation.

\section{Conclusion}

Magnesium oxide nanoparticles enhancing healing with minimal pathological changes at the surgical site.

\section{Acknowledgments}

The authors wish to express their thank to college of veterinary medicine, in both University of Mosul and University of Baghdad, to support this stud.

\section{Conflict of interest}

No conflict of interest.

\section{References}

1. Yhee JY, Im J, Nho RS. Advanced therapeutic strategies for chronic lung disease using nanoparticle-based drug delivery. J Clin Med. 2016;5(9):82-95. DOI: $\underline{10.10 .3390 / j \mathrm{~cm} 5090082}$

2. Malik ZJ, Eesa MJ. Laparoscopic partial splenectomy by using two techniques in goats. Iraqi J Vet Med. 2015;39(1):56-61. DOI: 10.30539/iraqijvm.v39i1

3. Nylund AM, Hoglund OV, Fransson BA. Thoracoscopic-assisted lung lobectomy in cat cadavers using a resorbable self-locking ligation device. Vet Surg. 2019;48(4):563-569. DOI: 10.10.1111/vsu.13109

4. Lee D, Jung BK, Roh TS, Kim SK. Ultrasonic dissection versus electrocautery for immediate prosthetic breast reconstruction. Arch Plast Surg 2020;47(1):20-25. DOI: 10.5999/aps.2019.00759

5. Tang ZX, Lv BF. MgO nanoparticles as antibacterial agent: preparation and activity. Braz J Chem Eng. 2014;31(3):591-601. DOI: $\underline{10.10 .1590 / 0104-6632.20140313 s 00002813}$

6. Bindhu MR, Umadevi M, Micheal KM, Arasu MV, Al-Dhabi NA. Structural, morphological and optical properties of $\mathrm{MgO}$ nanoparticles for antibacterial applications. Mat Let. 2016;166(1):19-22. DOI: $\underline{10.1016 / \text { j.matlet.2015.12.020 }}$

7. Zhao Y, Liu B, You C, Chen M. Effects of $\mathrm{MgO}$ whiskers on mechanical properties and crystallization behavior of PLLA/MgO $\begin{array}{llll}\text { composites. Mat Desi. 2016;89(5):573-581. DOI: } & \end{array}$ 10.1016/j.matdes.2015.09.157

8. Starlinger P, Assinger A. Importance of platelet-derived growth factors in liver regeneration. Exp Rev Gast Hepat. 2016;10(5):557-559. DOI: 10.1586/17474124.2016.1158100

9. Basso W, Grandt LM, Magnenat AL, Gottstein B, Campos M. Strongyloides stercoralis infection in imported and local dogs in Switzerland: from clinics to molecular genetics. Parasitol Res. 2019;118(1):255-266. DOI: 10.1007/s00436-018-6173-3

10. Ko JC. Anesthesia and pain management in dogs and cats. UK: Manson Publishing Ltd; 2013. 92-93 p.

11. Hosseini SV, Dehghani M, Khazraei H, Karami MY, Karbasi S Banihashmi SH. Human amniotic membrane effect on colorectal anastomosis in dogs undergoing radiotherapy with/without diverting stoma: An experimental preliminary study. Int $\mathrm{J}$ Radiat Res. 2017;15(2):213-218. DOI: 10.18869/acadpub.ijrr.15.2.213

12. Moeini-Nodeh S, Rahimifard $\mathrm{M}$, Baeeri $\mathrm{M}$ and Abdollahi $\mathrm{M}$. Functional improvement in rats' pancreatic islets using magnesium oxide nanoparticles through antiapoptotic and antioxidant pathways. Biol Trace Elem Res. 2017;175(1):146-155. DOI: 10.1007/s12011016-0754-8

13. Systat Software Inc. Sigma plot V12.0/SYSTAT software. UK; 2016.

14. Kurz A. Physiology of thermoregulation. Best Pract Res Clin Anaesthesiol. 2008;22(4):627-644. DOI: 10.1016/j.bpa.2008.06.004

15. Maji J, Pandey S, Basu S. Synthesis and evaluation of antibacterial properties of magnesium oxide nanoparticles. Bullet Mate Sci. 2020;43(1):25-35. DOI: $10.1007 / \mathrm{s} 12034-019-1963-5$

16. Erol Y, Ergonul AG, Ozdil A, Nalbantgil S, Cagırıcı U, Turhan K, Cakan A. Assessment of cardiac complications in patients undergoing pulmonary resection. Heart Lung Circ. 2019;28 (7):1099-1101. DOI: 10.1016/j.hlc.2018.08.019

17. Wakamatsu I, Matsuguma H, Nakahara R, Chida M. Factors associated with compensatory lung growth after pulmonary lobectomy for lung malignancy: an analysis of lung weight and lung volume changes based on computed tomography findings. Surg Today. 2020;50(2):144-152. DOI: 10.1007/s00595-019-01863-0

18. Kim SJ, Lee YJ, Park JS, Cho YJ, Cho S, Yoon HI, Kim K, Lee JH, Jheon $\mathrm{S}$, Lee CT. Changes in pulmonary function in lung cancer patients after video-assisted thoracic surgery. Ann Thora Surg. 2015;99(1):210217. DOI: $10.1016 /$ j.athoracsur.2014.07.066

19. Taşkin H, Telli AO, Yuncu G, Taşpinar B, Yalman A, Senol H. Postoperative respiratory muscle training in addition to chest physiotherapy after pulmonary resection: A randomized controlled study. Physio Theory Pract. 2018;(1):1-8. DOI: 10.1080/09593985.2018.1488189

20. Karenovics W, Licker M, Ellenberger C, Christodoulou M, Diaper J, Bhatia C, Robert J, Bridevaux PO, Triponez F. Short-term preoperative exercise therapy does not improve long-term outcome after lung cancer surgery: A randomized controlled study. Eur J Cardiothora Surg. 2017;52(1):47-54. DOI: 10.1093/ejcts/ezx030

21. Torabi M, Kesmati M, Pourreza N, Najafzadeh Varzi H, Galehdari H. Neurobehavioral and biochemical modulation following administration of $\mathrm{MgO}$ and $\mathrm{ZnO}$ nanoparticles in the presence and absence of acute stress. Life Sci. 2018;203(1):72-82. DOI: 10.1016/j.lfs.2018.04.023

22. Maggiore SM, Battilana M, Serano L, Petrini F. Ventilatory support after extubation in critically ill patients. Lan Respir Med. 2018;6(12):948-962. DOI: 10.1016/S2213-2600(18)30375-8

23. Nomori H, Shiraishi A, Cong Y, Sugimura H, Mishima S. Differences in postoperative changes in pulmonary functions following segmentectomy compared with lobectomy. Eur J Cardiothorac Surg. 2018;53(3):640-647. DOI: 10.1093/ejcts/ezx357

24. Störmann P, Wagner N, Kohler K, Auner B, Simon TP, Pfeifer R, Horst K, Pape HC, Hildebrand F, Wutzler S, Marzi I, Relja B. Monotrauma is associated with enhanced remote inflammatory response and organ damage, while polytrauma intensifies both in porcine trauma model. Eur J Trauma Emer Surg. 2020;46(1):31-42. DOI: 10.1007/s00068019-01098-1

25. Qiao Z, Wang W, Yin L, Luo P, Greven J, Horst K, Hildebrand F. Using IL-6 concentrations in the first $24 \mathrm{~h}$ following trauma to predict immunological complications and mortality in trauma patients: a meta- 
analysis. Eur J Trauma Emer Surg. 2018;44(5):679-687. DOI: 10.1007/s00068-017-0880-9

26. Das BC, Alam SMK, Nashid ZF, Khan AS, Khan ZR. Change in serum interleukin-6 levels in patients after pancreatoduodenectomy for periampullary cancer. BSMMU J. 2017;10(1):11-15. DOI: 10.3329/bsmmuj.v10i1.31311

27. Moeini-Nodeh S, Rahimifard M, Baeeri M, Abdollahi M. Functional improvement in rats' pancreatic islets using magnesium oxide nanoparticles through antiapoptotic and antioxidant pathways. Biol Trace Elem Res. 2017;175(1):146-155. DOI: 10.1007/s12011-0160754-8

28. Faz-Lopez B, Mayoral-Reyes H, Hernandez-Pando R, Martinez-Labat P, McKay DM, Medina-Andrade I, Olguin JE, Terrazas LI. A Dual role for macrophages in modulating lung tissue damage/repair during L2 Toxocara canis infection. Pathogens 2019;8(4):280-305. DOI: 10.3390/pathogens 8040280

29. Liu C, Tang J. Expression levels of tumor necrosis factor- $\alpha$ and the corresponding receptors are correlated with trauma severity. Oncol Lett. 2014;8(6):2747-2751. DOI: $10.3892 / \mathrm{ol} .2014 .2575$

30. Fehaid A, Taniguchi A. Silver nanoparticles reduce the apoptosis induced by tumor necrosis factor- $\alpha$. Sci Technol Adv Mater. 2018;19(1):526-534. DOI: 10.1080/14686996.2018.1487761

31. Shapouri-Moghaddam A, Mohammadian S, Vazini H, Taghadosi M, Esmaeili SA, Mardani F, Seifi B, Mohammadi A, Afshari JT, Sahebkar A. Macrophage plasticity, polarization, and function in health and disease. J Cell Physiol. 2018;233(9):6425-6440. DOI: $\underline{10.1002 / \mathrm{jcp} .26429}$

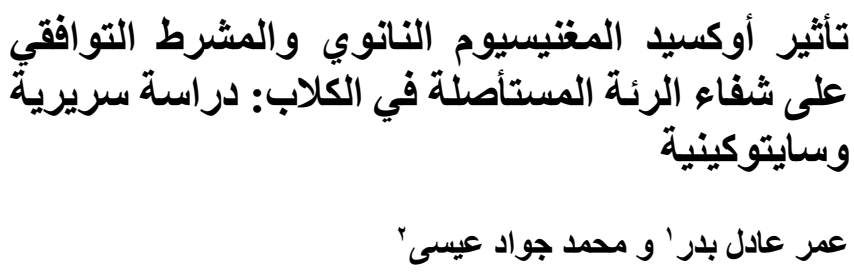

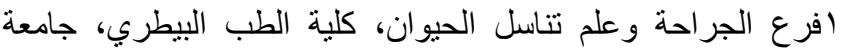

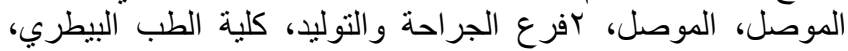

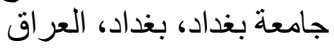

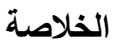

هدفت هذه الدراسة على تقييم تأثثير الجسيمات النانوية من أوكسبد النجيد

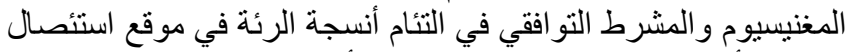

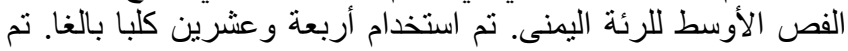

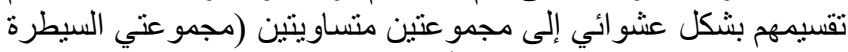

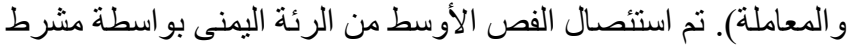

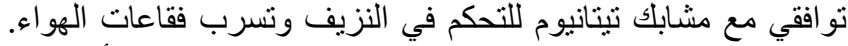

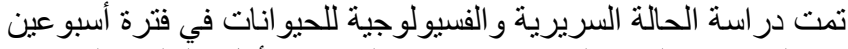

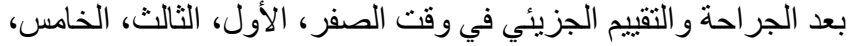

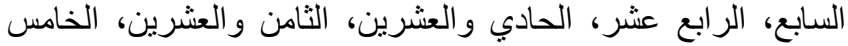

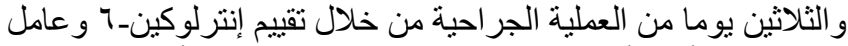

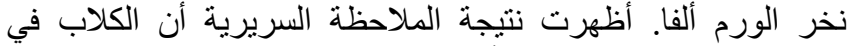

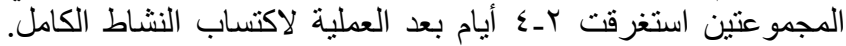

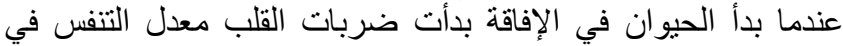

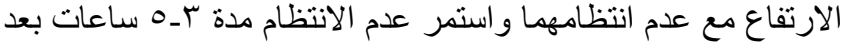

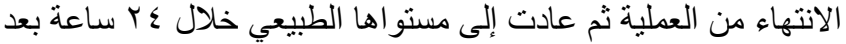

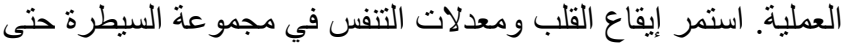

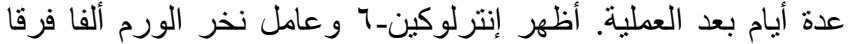
معنويا لهذين العاملين بين مجمو عة السيطرة والمعالجة. 